\title{
MEIOS ADEQUADOS DE SOLUÇÃO DE CONFLITOS COMO DISPOSITIVOS DO PLURALISMO JURÍDICO E DA EMANCIPAÇÃO POPULAR
}

\author{
Yuri Matheus Araujo Matos ${ }^{1 *}$ \\ Luciana de Aboim Machado $2 * *$ \\ Amanda Inês Morais Sampaio ${ }^{3 * * *}$
}

\begin{abstract}
RESUMO
São examinados, na presente pesquisa, os meios adequados de solução de conflitos como formas de mitigação dos vícios inerentes à concepção clássica de prestação jurisdicional. Estuda-se o crescimento do uso da autocomposição nos Estados Unidos da América nos últimos 15 (quinze) anos, bem como a introdução das suas principais técnicas ao ordenamento jurídico brasileiro. Consequentemente, são observados os possíveis reflexos sobre a participação democrática na formação das normas através do judiciário. Conclui-se pela os meios adequados de solução de conflitos são dispositivos contemporâneos em prol da emancipação popular. Para o desenvolvimento da pesquisa foi realizado uma revisão bibliográfica e documental.
\end{abstract}

Palavras-chave: Autonomia; Efetividade jurisdicional; Pluralismo jurídico; Tutela jurisdicional; Sistema multiportas.

\footnotetext{
1 *Mestrando no Programa de Pós-graduação em Direito pela Universidade Federal de Sergipe (PRODIR/UFS), bolsista pela CAPES. Graduado em Direito pela Universidade Federal de Sergipe. Tem experiência na área de Direito, com ênfase em Direito Tributário, atuando principalmente nos seguintes temas: Tributação do Consumo; Mediação e Conciliação. Membro dos Grupos de Pesquisa Eficácia dos Direitos Humanos e Fundamentais: seus reflexos nas relações sociais (GEDH/UFS/CNPq). Advogado. E-mail: ymam1996@ hotmail.com.

2 ***Pós-doutora em Direito pela Universidade Federal da Bahia e pela Università Degli Studi G. d'Annunzio (Italia). Doutora em Direito do Trabalho pela Faculdade de Direito da Universidade de São Paulo. Mestre em Direito do Trabalho pela Pontifícia Universidade Católica de São Paulo (PUC/SP). Especialista em Direito do Trabalho e em Direito Processual Civil (PUC/SP). Professora Associada da Universidade Federal de Sergipe. Coordenadora do Programa de Pós-Graduação "stricto sensu" em Direito da Universidade Federal de Sergipe. Líder do grupo de pesquisa CNPQ "Eficácia dos direitos humanos e fundamentais: seus reflexos nas relações sociais". E-mail: lucianags_adv@uol.com.br

3 ** Mestranda no Programa de Pós-graduação em Direito pela Universidade Federal de Sergipe (PRODIR/UFS), bolsista pela CAPES. Graduada em Direito pela Universidade Tiradentes (UNIT), com bolsa sanduíche na Universidad de Sevilla/ES. Membro dos Grupos de Pesquisa Eficácia dos Direitos Humanos e Fundamentais: seus reflexos nas relações sociais (GEDH/UFS/CNPq), Educação e Contemporaneidade (EDUCON/UFS/CNPq) e Direito Público, Educação Jurídica e Direitos Humanos na Contemporaneidade (PEJDH/UNIT/CNPq). Pósgraduada lato sensu em Direito Processual Civil pela Escola Judicial do Estado de Sergipe (EJUSE). Advogada. E-mail: amandaimsampaio@gmail.com.
} 


\title{
APPROPIATE DISPUTE RESOLUTION AS DEVICES OF LEGAL PLURALISM AND POPULAR EMANCIPATION
}

\begin{abstract}
The switable techniques of conflicts solutions are examinated as ways of mitigation of the vices inherentto the classical conception of adjudication. The growth of the autocomposition use in United States America in the last 15 (fifteen) years is studied, such as the introduction of the main techniques in the brazilian legal order. Consequently, the possible reflexes of democratic participation in the rules formation through the judiciary. It is concluded that the appropriate means of conflict resolution are contemporary devices in favor of popular emancipation. For the development of the research, a bibliographic and documentary review was carried out.
\end{abstract}

Keywords: Autonomy; Jurisdictional Effectiveness; Jurisdictional protection; Legal pluralismo; Multiport system.

\section{INTRODUÇÃO}

Não obstante a relevância do monismo jurisdicional para a formação civilizatória, é constatado o encarecimento do respectivo serviço pela alta demanda sem correspondente oferta; excesso de procedimentalismo; e, consequentemente, mitigação da aceitação social sobre o fundamento das decisões judiciais.

Adota-se como paradigma a compreensão que a resolução alternativa de litígios é eficiente para a eficácia da prestação jurisdicional. Como hipótese principal, que a adequação dos institutos inerentes à autocomposição ao negócio jurídico processual possui aptidão para promover a efetividade processual. Adota-se a hipótese secundária que a mediação de conflitos promove o diálogo racional público. Consequentemente, que, com o pluralismo político, o debate sobre o próprio processo possui o condão de promover a emancipação popular. Esta seria instrumento eficaz para a melhoria da qualidade de vida dos cidadãos.

Utiliza-se como metodologia a consulta doutrinária e jurisprudência, com enfoque hermenêutico, e de artigos científicos acerca do tema. Além disso, pesquisa de bancos de dados 
do Conselho Nacional de Justiça sobre entraves processuais e de estudos estadunidenses acerca dos efeitos da mediação de conflitos sobre a sua respectiva sociedade.

\section{COMPREENSÃO CLÁSSICA DA TUTELA JURISDICIONAL}

As divergências na percepção e na concretização dos direitos objetivos ${ }^{4}$, inerentes à democracia $^{5}$, demandam contenção social ${ }^{6}$. Dentre os legitimados à sua realização, assume o Estado essa obrigação como fato consectário do contratualismo ${ }^{7}$. Diante de diversas técnicas aptas a esse fim, a ciência jurídica majoritária brasileira opta por lançar mão da jurisdição, em seu aspecto clássico.

Os contornos da jurisdição são objeto de detidos estudos, com enfoque na verticalidade da relação. Isto é, o Estado julgador determina e os particulares (e o próprio Estado administrador) executam as suas determinações. Logo, conceitua-se a jurisdição como função atribuída a terceiro imparcial de realizar o direito de modo imperativo e criativo, reconhecendo, efetivando, protegendo ou integrando situações jurídicas concretamente deduzidas, mediante decisão insuscetível de controle externo, com aptidão para a coisa julgada (CHIOVENDA, p. 1969, p. 15).

\footnotetext{
4 "Primeiro: cada pessoa deve ter um direito igual ao mais abrangente sistema de liberdades básicas iguais que seja compatível com um sistema semelhante de liberdades para as outras. Segundo: as desigualdades sociais e econômicas devem ser ordenadas de tal modo que sejam ao mesmo tempo (a) consideradas como vantajosas para todos dentro dos limites do razoável, e (b) vinculadas a posições e cargos acessíveis a todos" (RAWLS, 1997, p. $64)$.

5 "Se a democracia supõe o pensamento divergente, isto é, os múltiplos discursos, ela tem de admitir uma heterogeneidade essencial. Então, o conflito é inevitável. Muito embora a palavra conflito, com frequência, seja empregada em sentido pejorativo, como algo que devesse ser evitado a qualquer custo, deve-se atentar que divergir é inerente a uma sociedade pluralista. Se os conflitos existem, evita-los é permitir que persistam, degenerem ou sejam camuflados. O que a sociedade democrática deve fazer com o conflito é trabalha-lo, de modo que, a partir da discussão, do confronto, sejam encontradas efetivas possibilidades de superação"(SPOSATO;SILVA, 2018. p. 12).

6 "Para abordar os conflitos, é importante entender o que os causa. Muitos fatores podem originá-los, merecendo destaque a limitação de recursos, a ocorrência de mudanças, a resistência a aceitar posições alheias, a existência de interesses contrapostos, o desrespeito à diversidade e a insatisfação pessoal. [...] Conflito de interesses qualificado por uma pretensão resistida" (TARTUCE, 2016, p. 5).

7 "A concepção formal da justiça a administração regular e imparcial das normas comuns, transforma-se no estado de direito quando se aplica ao sistema jurídico. Um tipo de ação injusta é a incapacidade, por parte de juízes e de outras autoridades, de aplicar a regra apropriada ou interpretá-la de forma correta" ((RAWLS, 1997. P. 257).
} 
As principais razões para a primazia do estudo e prática jurisdicionais coincidem com o seu escopo. Em relação à imparcialidade do terceiro, é obtida através do seu afastamento objetivo da lide (por ser estranho ao problema), e subjetivo ${ }^{8}$, ante a ausência de suspeição e impedimento. Permite, em tese, a concretização da imparcialidade de John Stuart Mill ${ }^{9}$.

Quanto à realização imperativa do direito, decorre do alcance da inafastabilidade da tutela jurisdicional ao polo passivo da demanda, que assegura o enforcement da atuação estatal e legitima socialmente a busca pela tutela jurisdicional. Trata-se de prerrogativa estatal apta a permitir a eficácia do seu comando. Isto porque "a jurisdição, além de irresistível, é imperativa; ela não é prestada de forma precária ou condicional, mas sim em atendimento a um objetivo que assinala sua qualidade terminativa e obrigatória” (TARTUCE, 2016, p. 137).

Outro benefício relevante está no uso de processo criativo jurisdicional. O juiz reconstrói o sistema jurídico a partir de um caso concreto, em dois momentos. No primeiro, cria a norma jurídica individualizada (coisa julgada material). No segundo, cria uma norma jurídica geral (ratio decidendi), que serve como padrão para a solução de casos futuros semelhantes.

$\mathrm{O}$ fundamento da atividade criativa reside na inafastabilidade da tutela jurisdicional e vedação ao non liquet (abertura por intermédio do fechamento). Consequentemente, obtém-se segurança através do primeiro aspecto e igualdade de tratamento pelo segundo, tornando a atividade judicial formalmente justa.

As funções da jurisdição ${ }^{10}$ de reconhecer, efetivar, proteger ou integrar situações jurídicas representam que todos os direitos em sentido amplo merecem proteção jurisdicional,

\footnotetext{
${ }^{8}$ Neste sentido: "A festejada distinção entre imparcialidade e neutralidade é um non sense. Ou seja, o julgador deve esforçar-se para reconhecer-se cognitivamente limitado e, a partir daí, proteger os outros e ele mesmo de si próprio. Dificilmente haverá um grau zero de parcialidade ou imparcialidade total, que propicie uma atmosfera "pura" de objetividade. Uma neutralidade asséptica de vieses é praticamente impossível. Todavia, embora sempre reste algum quid de enviesamento, vale a pena lutar contra ele. Ao fim e ao cabo, essa batalha se confunde com a própria luta da Civilização contra seus atavismos, irracionalidades, quase-racionalidades e animalidades ancestrais, que ao longo da história insistem em assaltar a humanidade. Daí a importância em caminhar em direção a esse ideal e desenvolver cada vez mais linhas de pesquisa em tecnologia comportamental" (COSTA, 2016, p.. 144).

9 "The creed which accepts as the foundation of morals, Utility, or the Greatest Happiness Principle, holds that actions are right in proportion as they tend to promote happiness, wrong as they tend to produce the reverse of happiness" (MILL, 1969, p. 210).

O credo que admite a Utilidade, ou Princípio da Máxima Felicidade, como o fundamento da moral, sustenta que as ações são corretas na proporção com que tendem a promover a felicidade, e erradas quando elas tendem a produzir o seu contrário. (Tradução livre) .

10 "Pode-se afirmar que o direito à jurisdição, de índole pública e subjetiva, desenvolve-se em três etapas que encadeiam e completam: o acesso ao poder estatal prestador da jurisdição, a eficiência e prontidão da resposta estatal à demanda deduzida e a eficácia da decisão proferida" (TARTUCE, 2016, p. 111).
} 
seja ela declaratória, constitutiva ou condenatória ${ }^{11}$. Trata-se de efetivar as garantias aos direitos decorrentes do sistema normativo em sentido amplo. Seu alcance horizontal de direitos e tutelas permite que a jurisdição seja instrumento da onipresença estatal e enseja, em tese, a resolução de todas as questões particulares. Seu limite é o exercício da jurisdição por encomenda. Isto é, está sujeita a um conflito de interesses qualificado por uma pretensão resistida ${ }^{12}$, fato que assegura a separação dos poderes.

A insuscetibilidade de controle externo garante a exclusividade do judiciário na sua atividade (a própria jurisdição se controla). Desta maneira, a decisão sobre os problemas próprios e alheios é revestida de segurança suficiente para, em tese, promover a pacificação social.

Diante dos benefícios da jurisdição apresentados pela doutrina clássica, reconhece-se a sua relevância para a harmonização das condutas. Em tese, as características supramencionadas são aptas ao alcance de fins sociais (pacificação do conflito, educação da sociedade), políticos (fortalecimento do Estado, último recurso em termos de proteção às liberdades, confere participação direta do jurisdicionado - democracia representativa e sociedade aberta aos intérpretes) e jurídicos (atuação da "vontade concreta da lei”).

Entretanto, reconhece-se vícios práticos na aplicação monista da primazia da tutela jurisdicional. O mais relevante é o encarecimento do serviço ${ }^{13}$ pela alta demanda sem correspondente oferta ${ }^{14}$. Como consequência, o procedimentalismo, em certa medida necessário para lidar com problemas em massa, mas que inevitavelmente alija os fundamentos

\footnotetext{
11 "Se a simples "descobreta" da autonomia das ações constitutivas por Schrutka Von Rechtenstamm já se constituiu num episódio marcante para a ciência processual, sucedendo o mesmo com as ações mandamentais por Georg Kuttner, o que se dirá da transformação de todas essas idéias ao contato de uma mente extremamente poderosa como a de Pontes de Miranda? A transformação opera-se pela aplicação do conceito de quantificação à Teoria das Ações. Ainda hoje há enorme resistência à aplicação desse tipo de raciocínio ao direito, em virude, especialmente, da distinção entre ciência do espírito (moral sciences) e as ciências da natureza.

[...] Classifica Pontes de Miranda as ações ou sentenças por seu efeito preponderante, sem excluir a existência simultânea dos demais efeitos. Os efeitos secundários se relacionariam uns em face dos outros segundo uma hierarquia, ou seja, na conformidade dos graus de eficácia próprios de cada ação ou sentença" (SILVA, 1988, p. 249-256).

${ }^{12}$ Há exceções nas quais não há lide, como tutela inibitória, controle abstrato, jurisdição voluntária.

${ }^{13}$ Observa-se com maior facilidade a dificuldade nos períodos de crise, a exemplo da ocasionada pelo SARSCovid 19. Sob o ponto de vista de prestação jurisdicional, o encarecimento da oferta enseja a dificuldade da sua ocorrência. Há consequentemente a majoração do financiamento através dos impostos (inevitavelmente retirando recursos de outros serviços), ou diretamente pelos próprios contribuintes (aqueles que não possuem justiça gratuita, nem se enquadram no conceito de Fazenda Pública ou Ministério Público), prejudicando o acesso à justiça. Frisese que, sob o ponto de vista da tutela jurisdicional declaratória e constitutiva, não há relevantes mudanças, exceto se o judiciário for "desaparelhado". Em relação às tutelas condenatórias, a complexidade reside na satisfatividade. 14 "Praticamente impossível que os quadros judiciários acompanhem o intenso crescimento da demanda" (TARTUCE, 2016, p. 9).
} 
dos fatos, tornando a análise tecnicista. Desta maneira, reduz-se a aceitação social sobre o fundamento da decisão, permanecendo (mas sendo gradativamente mitigada) a obediência ao dispositivo, somente.

\section{TUTELAS ALTERNATIVAS E O ACESSO À JUSTIÇA}

$\mathrm{O}$ acesso à justiça não coincide com o acesso à tutela jurisdicional, sendo este uma espécie daquele. Explica Tartuce (2016, p. 6) que "satisfazer alguém, contudo, tende a ser algo mais complexo do que simplesmente lhe apresentar a resposta oferecida pelo ordenamento jurídico". Compreende-se que há outros meios aptos à resolução dos problemas sociais - para cada espécie de problema um ou outro mais eficaz ${ }^{15}$. Portanto, não se objetiva infirmar a apreciação jurisdicional, mas compreender que outras técnicas podem ser mais eficazes que o mandamento judicial, a depender do caso.

Trata-se da base do sistema multiportas, que reconhece a relevância da arbitragem $^{16}$ (não obstante seja também espécie de jurisdição), autotutela e autocomposição, além de

\footnotetext{
${ }^{15}$ A resolução natural dos conflitos não ocorre no judiciário, mas mediante a composição direta entre as partes. Por este motivo, na análise da obrigação como um processo, explica Clóvis Veríssimo de Couto e Silva que "A obrigação dirige-se à prestação, ao ato que a satisfaça."

SILVA, Clóvis Veríssimo de Couto e. A obrigação como processo. Rio de Janeiro: Editora FGV, 2006. P. 59-60 16 "A arbitragem pode ser empregada para resolver disputas em que não haja divergência moral, ou seja, em que as pretensões controvertidas não são pautadas por valores de justiça" (SPOSATO; SILVA, 2018, p. 16).
} 
institutos derivados, como o med-arb ${ }^{17}$, minitrial ${ }^{18}$, dispute board $^{19}$, fact-finding ${ }^{20}$, summary jury trial $^{21}$, termo de ajuste de conduta ${ }^{22}$, baseball administration ${ }^{23}$ e avaliação neutra de terceiro $^{24}$, para a pacificação social (TARTUCE, 2016, p. 15-16). Atua em sintonia com a terceira onda de acesso à justiça apresentada por Mauro Cappelletti e Bryant Garth, em Acesso à Justiça: "esse enfoque reconhece a necessidade de correlacionar e adaptar o processo civil ao tipo de litígio. Existem muitas características que podem distinguir um litígio de outro" (CAPPELLETTI; GARTH, 1988, p. 71).

Em relação à autotutela, o próprio Estado a criminaliza, em regra, em virtude do monopólio da força ${ }^{25}$. Em alguns casos, contudo, é permitida. Trata-se do desforço imediato, no esbulho, legítima defesa, apreensão de bem com penhor legal, autoexecutoriedade pelo

\footnotetext{
17 "O enfrentamento do conflito começa com uma mediação; caso as partes não alcancem, parte-se para a arbitragem; há também a variação arb-med, em que a sequência muda" (TARTUCE, 2016, p. 153).

18 "Utilizado geralmente para resolver disputas que podem ser objeto de litigância demorada, visa à obtenção de uma solução mutuamente satisfatória; por ser talhado às necessidades dos participantes, podem agregar diversas técnicas. As partes, por seus advogados, apresentam suas teses a um consultor neutro, geralmente um advogado com experiência em relevantes áreas jurídicas, que dará sua opinião sobre o que ocorreria se o caso estivesse no tribunal; a partir de então as partes voltam a negociar um acordo, com ou sem a presença do consultor neutro" (TARTUCE, 2016, p. 154).

${ }^{19}$ Instituto de crescimento recente de uso no âmbito nacional é o dispute board. É criado um Comitê de Prevenção de Disputas, com o fim de identificar problemas no seu início. Pode-se realizar dispute review board (recomendações não obrigatórias para as partes, mas vinculantes caso aceitem expressamente); dispute adjudication board (vinculantes desde o início) e combined dispute board (recomendações e decisões, em caráter misto. Podem ser permanentes ou ad hoc. Sobre o tema, o Conselho de Justiça Federal promoveu a I Jornada sobre Prevenção e Solução Extrajudicial de Litígios, e foram criados três enunciados:

Enunciado 49: informa que o dispute board tem fundamento no art. $3^{\circ}$, $\S^{\circ}$, do Código de Processo Civil, por ser método de solução consensual.

Enunciado 76: as decisões do dispute board vinculam até que o judiciário ou juízo arbitral competente emitam nova decisão ou a confirmem.

Enunciado 80: recomenda a técnica para contratos de construção ou infraestrutura (obras), como mecanismo voltado à prevenção de litígios e à redução dos custos correlatos.

20 "Constitui o meio pelo qual um terceiro imparcial é escolhido para identificar fatos relevantes para a causa; sua atuação pode contribuir para avanços na negociação, na mediação ou na solução judicial” (TARTUCE, 2016, p. 154).

${ }^{21}$ Trata-se de uma simulação de júri, com decisão não vinculativa às partes, mas que pode auxiliar na estruturação do acordo.

${ }^{22}$ São títulos executivos extrajudiciais que poupam o processo de conhecimento, como instrumentos à efetividade da tutela processual. Estimulam a observância voluntária dos direitos, obrigações e deveres, preservam a imagem empresarial, reduzem custos processuais e coincidem os interesses das sociedades empresárias (em especial) com o interesse público primário (TARTUCE, 2016, p. 45).

23 "As partes negociam e submetem duas possíveis soluções a um árbitro, que deve optar por uma delas" (TARTUCE, 2016, p. 155).

24 "Contam com a assistência de um conhecedor prático e neutro para identificar pontos em que elas discordam ou concordam, fornecendo uma análise da tese de cada lado. Ele pode ainda predizer o possível resultado caso a demanda vá a juízo, bem como oferecer auxílio às partes em um processo de negociação" (TARTUCE, 2016, p. 155).

${ }^{25}$ Giuseppe Chiovenda explica que o reforço da organização política enseja a restrição à autodefesa, em virtude da natural expansão da atuação estatal (CHIOVENDA, 2000, p. 58).
} 
poder público, direito de retenção, greve, e até mesmo a guerra, desde que comunicado o Conselho de Segurança, conforme previsto no art. 51 da Carta das Nações Unidas (NAÇÕES UNIDAS, 1945, n.p.). Em virtude do seu caráter eminentemente privado, é a única forma de resolução de conflitos que pode ser amplamente revista pelo judiciário. Os parâmetros de revisão são semelhantes aos previstos na seara criminal: “injusta agressão, reação imediata e proporcionalidade nos meios de defesa" (TARTUCE, 2016, p. 21).

A autocomposição, por sua vez, é a solução consensual dos conflitos. Pode ocorrer mediante a transação (concessões mútuas entre as partes) ou submissão (abdicação voluntária). Se em juízo, é a renúncia do autor ou reconhecimento jurídico do pedido, do réu ${ }^{26}$.

A mediação e a conciliação, espécies autocompositivas, serão objeto de estudo deste capítulo. Reconhece-se a sua aptidão superior ao mandamus jurisdicional à resolução de determinados casos. É meio econômico e eficaz de desenvolvimento da cidadania, através da participação popular - e instrumento para a concretização da sociedade aberta aos intérpretes da norma ${ }^{27}$.

Por esse motivo a Resolução n. 125 de 2010 do Conselho Nacional de Justiça (CNJ) a estabelece como política pública, sendo o próprio CNJ o seu organizador. Determina a criação de Centros Judiciários de Solução de Conflitos e Cidadania; regulamenta a atuação do mediador e conciliador, criando seu Código de Ética; ordena a criação de banco de estatísticas e currículo mínimo para o curso de capacitação dos profissionais da área ${ }^{28}$.

A mais relevante diferença entre a mediação e a conciliação é que esta não pressupõe vínculo anterior entre as partes, mas aquela sim. Além disso, o mediador não propõe soluções, mas o conciliador pode (TARTUCE, 2016, p. 47). As semelhanças entre os institutos são:

\footnotetext{
${ }^{26}$ Observe-se que a submissão em juízo demanda homologação pelo juiz, prolatando sentença de mérito, com formação de coisa julgada material.

${ }^{27}$ Esta é a razão da relevância da publicidade processual. A sua relevância para o processo autocompositivo é notória. Por esta razão, as suas restrições, que são exceções, devem ser objeto de interpretação sempre restrita. De fato, inexiste direito fundamento para a aplicação dos direitos nos casos concretos, sob a perspectiva principiológica de Dworkin. Isto é, havendo dois direitos em sentidos diferentes, um prevalecerá no caso concreto, sem excluir completamente a aplicabilidade do outro. Como medida restritiva e excepcional, e que envolve a ponderação de princípios, a proporcionalidade é aplicável às questões daí decorrentes. Além disso, na restrição ao direito da sociedade à informação deve-se preservar limites: há um núcleo essencial intransponível, estabelecido na teoria dos limites dos limites (Schranken-Schranken): dignidade da pessoa humana; exigência de clareza e precisão; limitações, em regra, de cunho geral e abstrato; e a mencionada proporcionalidade (necessidade, adequação e proporcionalidade em sentido estrito). Além disso, a comunicação em massa é fato que não se pode ignorar e deve ser prestigiado. Um processo sem abertura à imprensa cai no abismo da ausência de correspondência entre a perspectiva pública e os fatos, estimulando a compreensão de um judiciário ilegítimo.

${ }^{28}$ Foi criado, com este fim, o Cadastro Nacional (e os Regionais) de Mediadores e Conciliadores, com dados pessoais, especialidade, referência de obtenção ou não de sucesso. Os mediadores são funcionários públicos ou profissionais liberais cadastrados.
} 
ambos retiram o juiz julgador da tentativa de mediar o conflito, preservando a confidencialidade; há maior estímulo às partes para resolverem seus próprios conflitos.

A autocomposição pode ocorrer extrajudicial ou judicialmente, como forma de se demonstrar que nem a sentença heterocompositiva nem a jurisdição como instituição são essenciais para a obtenção da justiça, em todos os casos. Além disso, possuem aptidão de irem além da regra da congruência, alcançando a lide sociológica e efetivamente pacificando o conflito ${ }^{29}$.

Na resolução direta entre as pessoas envolvidas há ampliação do objeto em análise, indo além do narrado no processo e daquilo que poderia ser considerado juridicamente relevante, do ponto de vista formal. Aproxima as partes do caso, permitindo o diálogo e a solução racional dos seus problemas, superando a demanda paternalista por um terceiro com suposta aptidão superior para solucionar o seu caso.

\section{PLURALISMO JURÍdICO E O PATERNALISMO}

Ao apresentar novas diretrizes para a segunda metade do século $\mathrm{XX}-\mathrm{e}$ ao terceiro milênio -, a Declaração Universal dos Direitos Humanos consagrou o marco histórico do constitucionalismo europeu. Fator incentivador da constitucionalização-releitura, promoveu profundas mudanças nas ordens processuais nacionais. Destaca-se, exemplificativamente, seu artigo XXI. $1^{30}$, que assegura o acesso aos serviços públicos nacionais ${ }^{31}$.

Entretanto, o processo assecuratório dos direitos pode carecer de disponibilidade político-econômica e gestão pública ${ }^{32}$. No caso brasileiro, a crise no processo de concretude

\footnotetext{
29 “Ao demandar em juízo, as partes muitas vezes omitem aspectos fáticos relevantes, levando ao conhecimento do magistrado apenas uma fatia da realidade verificada. A outra parte, por sua vez, pode incorrer na mesma conduta, apresentando apenas os fatos que repute favoráveis à sua "tese jurídica". O processo acaba limitado a um panorama deliberadamente recortado, o que pode gerar intensas dificuldades para a reconstituição histórica dos elementos relevantes e a conclusão sobre o que é realmente justo" (TARTUCE, 2016, p. 87).

30 "Art. XXI.1 Todo ser humano tem o direito d'e fazer parte no governo de seu país diretamente ou por intermédio de representantes livremente escolhidos" (NAÇÕES UNIDAS, 1948).

31 "O cerne do acesso à justiça não é possibilitar que todos possam ir à corte, mas sim que a justiça possa ser realizada no contexto em que se inserem as pessoas, com a salvaguarda da imparcialidade da decisão e da igualdade efetiva das partes" (TARTUCE, 2016, p. 77).

32 "A norma constitucional não tem existência autônoma em face da realidade. A sua essência reside na sua vigência, ou seja, a situação por ela regulada pretende ser concretizada na realidade. Essa pretensão de eficácia (Geltungsanspruch) não pode ser separada das condições históricas de sua realização, que estão, de diferentes
} 
dos direitos é agravada em decorrência do "grau de desigualdade e heterogeneidade superior ao observado na grande maioria dos países que desenvolveram sistemas de proteção social" (DAIN, 1995, p. 33). Com precária organização arrecadatória e má alocação redistributiva, a concretização dos direitos humanos resta prejudicada.

Uma das principais razões para o problema acima descrito reside na distância entre as instituições e seus principais destinatários, tornando o processo de tomada de decisão dos gestores públicos menos adequado à realidade social. Tanto o poder legislativo quanto o executivo e o jurisdicional sofrem de semelhante dilema, com suas peculiaridades inerentes. Concentra-se este trabalho na tomada de decisão do poder jurisdicional, em decorrência da ausência de eleição pelo voto direto e da necessidade de legitimação das decisões pela publicidade e fundamentação.

Objetiva-se apresentar a relevância do papel do pluralismo das ideias na tomada efetiva das decisões de poder, em processo retroalimentado de emancipação popular³. Afinal, "no processo democrático, o acesso à justiça desempenha um relevante papel de habilitar o cidadão a tutelar seus interesses e possibilitar à sociedade a composição pacífica de conflitos" (TARTUCE, 2016, p. 77). Desta maneira, não se busca ressaltar o âmbito institucionalista ${ }^{34}$, mas a relevância da participação do povo na tomada de decisões no âmbito judiciário, com o fim de construir sua própria realidade social ${ }^{35}$. Desta maneira, ensina a melhor doutrina que "os afluentes continuariam sendo afluentes [...] mas os pobres fariam parte do sistema político" (GALBRAITH, 1996. p. 162-164).

Há análise específica em relação à atuação da sociedade na interpretação das leis, inclusive nas salas até então relativamente "reservadas ao poder judiciário". Afinal, com o movimento neoconstitucionalista e ampliação da jurisdição constitucional, inclusive mediante

\footnotetext{
formas, numa relação de interdependência, criando regras próprias que não podem ser desconsideradas" (HESSE, 1991, p. 15).

${ }^{3}$ Não basta o gasto em grandes estruturas econômicas sem a respectiva capacidade educacional para gestão e convivência. John Kenneth Galbraith magistralmente ensina: "A transição da pobreza ao desenvolvimento econômico bem-sucedido envolvia basicamente a transferência da "mobília pesada" da economia desenvolvida [...] ignoraram-se ou se omitiram as duas maiores necessidades previamente mencionadas: uma ordem política estável e educação geral para as massas [...] Neste mundo, não existe população letrada que seja pobre, nem população analfabeta que não seja" (GALBRAITH, 1996, p. 151-153).

34 “A justiça está fundamentalmente conectada ao modo como as pessoas vivem e não meramente à natureza das instituições que as cercam” (SEN, 2018, p 12).

35 “O padrão de intervenção do Estado brasileiro concentrou-se no financiamento da acumulação e de expansão do capital, em detrimento da consolidação das instituições democráticas e da institucionalização do acesso público a bens serviços e direitos básicos de extensas camadas da população trabalhadora" (RAICHELIS, 1998, p. 66).
} 
a constitucionalização das políticas públicas, passa o judiciário a examinar a forma da sua efetivação. Garantir que o povo participe do respectivo processo de tomada de decisão pode significar sua autonomia e influência na gestão da coisa pública, direta e indiretamente.

Mediante um diálogo racional com amplitude de interlocutores, há maior chance de obtenção de uma análise $\operatorname{arrazoada}^{36}$, com o fim de assegurar com maior eficácia os direitos fundamentais ${ }^{37}$. O argumento em favor do diálogo aberto é que "não depende de que esta seja uma via infalível para acertar (tal via não pode existir), mas de que seja tão objetiva quanto for razoavelmente possível" (SEN, 2018, p. 12).

Ademais, o pluralismo de interlocutores permite que se desvincule de uma imparcialidade fechada (como pensamento paroquialista), aproximando-se assim de uma abordagem de um "espectador imparcial” de Adam Smith $\left(2018\right.$, p. 165) ${ }^{38}$, ressaltada por Sen em “A Ideia de Justiça”. Permite-se, em tese, a concretização da imparcialidade de John Stuart $\mathrm{Mill}^{39}$.

Mediante a abertura do debate racional ao público e a democracia participativa, constata-se o acesso à justiça ${ }^{40}$ como instrumento de efetivação da cidadania ${ }^{41}$. Através deste processo de mitigação do institucionalismo estritamente formal ${ }^{42}$, heteronormativo e,

\footnotetext{
36 "A racionalidade da escolha de uma pessoa não depende de quanto ela sabe, mas apenas da eficiência de seu raciocínio a partir de qualquer informação que tenha, por mais incompleta que seja. Nossa decisão é perfeitamente racional, contanto que encaremos as circunstâncias e façamos o melhor possível. Assim, as partes podem, de fato, tomar uma decisão racional, e certamente algumas das concepções alternativas de justiça são melhores que outras." (RAWLS, 1997, p. 439).

37 "Nenhum projeto de repartição pode deixar de responder a estas três perguntas: igualdade sim, mas entre quem, em relação a que e com base em quais critérios?" (BOBBIO, 1992, p. 97).

${ }^{38}$ Observe-se que "o "espectador imparcial" de Adam Smith é naturalmente um dispositivo para escrutínio crítico e a discussão pública. Ele não precisa, portanto, buscar a unanimidade ou o acordo total da mesma maneira que a camisa de força institucional da teoria rawlsiana da justiça exige" (SEN, 2018, p. 165).

39 "The creed which accepts as the foundation of morals, Utility, or the Greatest Happiness Principle, holds that actions are right in proportion as they tend to promote happiness, wrong as they tend to produce the reverse of happiness" (MILL, 1969, 2010).

O credo que admite a Utilidade, ou Princípio da Máxima Felicidade, como o fundamento da moral, sustenta que as ações são corretas na proporção com que tendem a promover a felicidade, e erradas quando elas tendem a produzir o seu contrário (tradução livre).

${ }^{40}$ Trata-se do bloco assecuratório da tutela jurisdicional, subdividido em indeclinabilidade e ubiquidade. Exclui limites totalitários ao direito de ação, une a jurisdição (afastando-se do modelo dual francês, à exceção do tribunal desportivo).

Sua tutela em âmbito material reside no acesso à ordem jurídica justa, que na prática aproxima o poder judiciário dos litígios da coletividade.

41 "A saída para a pobreza tende a ser visualizada exclusivamente através da construção de identidades coletivas, de novas formas de sociabilidade que dêem sustentação a uma moderna concepção de cidadania, mantida intocada a organização do mundo do trabalho" (IAMAMOTO, 1993a, p. 11).

42 "Se parte do problema da Justiça brasileira parece ser consequência do "voluntarismo irracional" dos operadores do direito, faz sentido insistirmos em reformas constitucionais, na mudança de leis e códigos e na positivação de
} 
consequentemente, do paternalismo ${ }^{4344}$, alcança-se algo mais próximo de uma sociedade aberta dos intérpretes da Constituição (HABERLE, 1997).

Desta maneira, a própria atuação jurisdicional resta controlada pela maior publicidade efetiva das decisões (com reconhecimento concreto) e consequente constrangimento decorrente dos limites da linguagem pública ${ }^{45}$. Neste sentido, aduz Lenio Streck (2017, p. 78) que "o solipsismo judicial (jurídico-interpretativo) só acontece em uma dada institucionalidade, em que existe uma baixa democracia" ${ }^{46}$. Desta maneira, há menor probabilidade de deturpação da teleologia dos princípios norteadores do sistema jurídico nacional ${ }^{47}$.

Diante dos fundamentos acima descritos, constata-se que uma maior participação popular no processo de tomada de decisão judicial sobre relevantes questões coletivas permite "uma transição de liberdades formais abstratas para as liberdades materiais, concretas" (SARLET, 2001, p. 51), garantindo assim a eficácia dos direitos fundamentais das diversas dimensões. Afinal,

Os pressupostos asseguradores da força normativa da Constituição não foram plenamente satisfeitos. A resposta à indagação sobre se o futuro do nosso Estado é uma questão de poder ou um problema jurídico depende da

novas regras? Não seriam elas mesmas preteridas em favor da aplicação de princípios amplos como tem acontecido nos últimos anos?” (LIMA; VASCONCELOS, 2019, p. 112).

43 Esse traço clientelista e vinculado à benemerência apresentou-se persistente por muitos anos na política assistencial brasileira" (COUTO, 2010, p. 103).

44 "Nosso reformismo larvar e inconcluso, nosso Estado burocratizado e impregnado de interesses particulares, nossa vida política repleta de clientelismo e fisiologia" (NOGUEIRA, 2011, p. 14).

${ }^{45}$ Para a compreensão geral dos atos processuais, deve-se desvencilhar do espírito obscurantista, marcado pelos jargões jurídicos e cultivo da mística como responsáveis pelo provincianismo intelectual do direito. Trata-se de limite material à efetividade da publicidade e da sociedade aberta promovida pela autocomposição dos conflitos. Para emancipar a população e fortalecer a cidadania, além de tornar o sujeito social ativo diante de decisões de difícil tradução para o cotidiano, deve-se evitar palavras rebuscadas e teorias internacionais advindas do direito comparado. A publicidade judicial deve considerar a violência linguística, em especial na audiência autocompositiva. O problema da linguagem não é restrito aos fundamentos jurídicos, mas alcança principalmente o procedimento. A clássica concepção de procedimento em contraditório que examina a pretensão resistida resta prejudicada caso as partes não compreendam aquilo que está sendo discutido nos ritos processuais. O caminho dos meios alternativos de resolução de conflitos talvez esteja mais inclusivo e informador ao dar palavra-ação para as partes.

${ }^{46} \mathrm{Na}$ mesma página complementa o autor: "Por isso o lema hermenêutico: deixemos que os textos nos digam algo. Deixemos que a Constituição dê o seu recado. Ela é linguagem pública. Que deveria constranger epistemicamente o seu destinatário, o juiz" (STRECK, 2019, p. 78).

47 “'Princípio' [...] sempre há de ser estudado sob a ótica das relações sintática e pragmática, cuidando-se de observar os princípios lógicos da identidade (um ser é igual a si mesmo) e da não-contradição (um ser, ao mesmo tempo, não é igual a si e igual a outro ser). [...] É um critério elaborado pela pragmática (comportamental) da comunicação jurídica e utilizado como base para o discurso deôntico" (BRITO, 1998, p. 66).

Diversas dentre as regras insculpidas no ordenamento jurídico são indevidamente denominadas princípios, com o exclusivo fim de lhes garantir maior efetividade cotidiana 
preservação e do fortalecimento da força normativa da Constituição, bem como de seu pressuposto fundamental, a vontade de Constituição. Essa tarefa foi confiada a todos nós (HESSE, 1991, p. 32).

Logo, a própria vontade da Constituição (Wille zur Verfassung) é privilegiada pela autonomia da vontade, como determinação basilar da mediação e conciliação ${ }^{48}$. Leciona Bobbio (1992, p. 78) que "um direito cujo reconhecimento e cuja efetiva proteção podem ser adiados sine die, além de confiado à vontade de sujeitos cuja obrigação de executar o programa é apenas uma obrigação moral, ou, no máximo, política, pode ser chamado corretamente de direito?”.

Serve a lição de substrato para o questionamento acerca do atrelamento entre a tomada de decisões públicas, o pós-positivismo e a força normativa da constituição ${ }^{49}$. Em especial a relevância da participação popular ativa no processo de formação da sua própria realidade. Decorre de hipótese específica adotada inicialmente neste projeto de pesquisa: “A autocomposição de litígios em regra possui maior chance de aceitação e pacificação social que a heterocomposição". Esta sentença parte do seguinte pressuposto: as normas criadas pelo próprio indivíduo possuem maior probabilidade de serem aceitas e cumpridas por ele.

Aproximar o povo dos tomadores de decisão (representantes) pode ensejar melhoria efetiva na sua qualidade de vida, por assegurar o fortalecimento do nexo entre as normas e os valores, e, especialmente, direcionar os julgamentos e as políticas públicas aos problemas reais da sociedade ${ }^{50}$.

O exercício da cidadania vai além do escrutínio e do voto. Seu aspecto mais relevante é o processo democrático da tomada das decisões públicas. Consequentemente, auxílio e efetiva resolução dos problemas sociais ${ }^{51}$. É relevante a participação popular em todos os órgãos de tomadas de decisões, inclusive o judiciário. Entretanto, diversos instrumentos construídos com esse fim podem estar sendo subutilizados, dentre os quais merece destaque a autocomposição dos litígios.

\footnotetext{
48 Segundo o princípio autocompositivo da autonomia da vontade, os conflitantes são os responsáveis pela definição do resultado das sessões de mediação e conciliação.

49 “É impossível a interpretação que não conduza ao bem estar da coletividade” (BRITO, 1998, p. 71).

50 “A utilização dos métodos autocompositivos, nos quais os envolvidos pacificam espontaneamente a disputa, representa um sinal de amadurecimento e de equilíbrio altamente desejado no meio social" (SPOSATO; MACHADO, 2018, p. 57).

51 “A pacificação social, importante e complexa missão constitucional do Estado, será mais bem alcançada com a participação ativa, em sua composição, de todos os envolvidos no conflito. A violência é mitigada, sendo substituída pelo respeito e pela consideração pelo outro" (TARTUCE, 2016, p. 344).
} 


\section{BENEFÍCIOS PRÁTICOS DO SISTEMA MULTIPORTAS}

Como reflexo prático do sistema multiportas, obtém-se a possibilidade de solução moral (com a autolimitação dos interesses pelos antagonistas), contratual (convenção mútua de composição do conflito) e arbitral (confiança a terceiro para a resolução) (TARTUCE, 2016, p. 26). Seu melhor método de atuação é o contraste da antiga figura da parte ou do negociador competitivo por um sistema com enfoque na cooperação processual, em sintonia com a nova processualística civil.

A mencionada positivação decorre do fortalecimento da teoria dos princípios, como espécies de normas constitucionais ou infraconstitucionais, com forte carga axiológica e diferença qualitativa entre si. Coaduna com o reconhecimento da força normativa da Constituição sobre a processualística civil, pois normas constitucionais são aplicadas direta e imediatamente, no limite da sua densidade jurídica, direcionando aos atores processuais a superação do modelo adversarial pelo cooperativo.

São reflexos do neoconstitucionalismo que, utilizados em sintonia com o aspecto procedimentalista do pós-positivismo (controle de excessos pelo judiciário, preservando-se a autonomia da vontade e a racionalidade individual e coletiva), apresentam a autocomposição como solução para o aumento da judicialização dos conflitos - outra consequência do fenômeno neoconstitucionalista.

A introdução dos referidos institutos na processualística pátria possui sintonia com propostas acadêmicas nacionais e externas. Destaca-se sobre o tema o Projeto de Negociação de Harvard, com estudo apresentado por Roger Fisher, William Ury e Bruce Patton (2005, p. 22) e o trabalho de José Maria Rossani Garcez (2004, p. 6-7). Apresentam princípios relevantes para a negociação, com o fim de superar o modelo adversarial, em favor da máxima concretude dos direitos envolvidos.

Com este fim, são adotadas técnicas relevantes para o método de negociação (TARTUCE, 2016, p. 43), sem detrimento daquelas já conhecidas ${ }^{52}$ :

\footnotetext{
${ }^{52}$ Independência: protege os mediadores e conciliadores, além de ser garantia dos conflitantes. Os mediadores e conciliadores não são obrigados a redigirem acordos ilegais ou inexequíveis, em sintonia com o art. $5^{\circ}$ do Código de Processo Civil de 2015.

Autonomia da vontade: quem define o resultado são os conflitantes, em prestígio à autonomia racional, conforme o art. 166, $\S 4^{\circ}$, do Código de Processo Civil, e o art. $2^{\circ}$, $\S 2^{\circ}$, da Lei n. 13.140 de 2015.

Confidencialidade: obrigatória de todas as informações recebidas ao longo da negociação. Os mediadores e conciliadores podem inclusive negar o depoimento como testemunhas. Todavia, o art. 166, § $1^{\circ}$ do Código de Processo Civil e arts. 30 e 31 da Lei n. 13.140 de 2015 apresentam algumas exceções: se as partes dispuserem de
} 
Não negociar sobre posições (geralmente fechadas), mas considerar os interesses; separar as pessoas dos problemas (tratando o outro sempre com respeito, confiança e consideração); fixar-se nos reais interesses envolvidos (desejos e preocupações) e não nas posições formais adotadas (de rigidez ou conduta fechada); imaginar, criativamente, opções alternativas, com ganhos recíprocos.

A aplicabilidade prática dos referidos princípios é objeto de estudo pelo referido Projeto de Negociação de Harvard. Observa através de pesquisa empírica a adoção das técnicas pelos atores processuais e seus efeitos sobre a própria concepção estadunidense de lide e processo. Em 2011 foi realizada relevante pesquisa, publicada no Harvard Negotiation Law Review (STIPANOWICH; LAMARE, 2014), com o objetivo de examinar os reflexos econômicos, sociais e à imagem das sociedades empresárias em decorrência do alternative dispute resolution (ADR), que engloba a autocomposição, a arbitragem e técnicas similares que não são objeto de previsão legal. Reiterou-se um estudo realizado 15 (quinze) anos antes com mil diferentes companhias, para a análise da evolução do instituto.

Foi constatado inicialmente que considerados "em grupo, os advogados das sociedades empresárias moderaram suas expectativas em relação à ADR. Por outro lado, mais empresas adotaram a mediação e preveem seu uso contínuo para um amplo espectro de disputas"53. Consequentemente, o papel do judiciário passou a residir no controle da abusividade das cláusulas e interpretação das decisões, permitindo às partes a construção dos parâmetros de direito material e processual considerados por elas relevantes para a resolução das lides ${ }^{54}$.

maneira diversa, se a divulgação for exigida por lei, se necessária a divulgação para cumprimento de acordo, ou se houver crime de ação pública, especialmente se envolver a administração tributária.

Imparcialidade: mediadores e conciliadores devem se declarar suspeitos ou impedidos, sob pena de punição e exclusão do cadastro. As hipóteses de suspeição e impedimento são as mesmas do juiz. Além delas, há o impedimento, por 1 (um) ano, do término da última audiência, de assessorar, patrocinar, qualquer das partes, conforme o art. $5^{\circ}$ da Lei n. 13.140 de 2015.

Oralidade: o ambiente de mediação e conciliação deve ser pessoal, presencial, oral, tornando o diálogo e a negociação mais leve.

Informalidade: o mediador não pode utilizar beca, nem linguajar rebuscado. Além disso, é necessária uma mesa de negociação circular, com cadeiras iguais e de mesma altura;

Decisão informada: para que os atores processuais decidam de maneira consciente.

Isonomia entre as partes, busca do consenso e boa-fé são outras bases relevantes da autocomposição.

53 "As a group, corporate attorneys have moderated their expectations for ADR. At the same time, more corporations have embraced mediation and foresee its continuing use for a wide spectrum of disputes";

(tradução livre) (STIPANOWICH; LAMARE, 2014, p. 3-4).

54 "In addition to encouraging or directing companies to mediate cases in litigation, courts are regularly being called upon to interpret and enforce varied, often complex contractual dispute resolution schemes."

Além de incentivarem ou orientarem as sociedades empresárias a mediarem casos em litígios, os tribunais são regularmente convocados a interpretarem e aplicarem diversas normas contratuais, muitas vezes complexas, de resoluções de disputas (tradução livre) (STIPANOWICH; LAMARE, 2014, p. 5). 
Trata-se de uma "revolução silenciosa" na forma de composição dos conflitos civis, cujo êxito quantitativo decorreu da atuação participativa dos advogados ${ }^{55}$, com sugestões, fuga dos vícios de "adversarismo", manipulação ou cooptação de mediadores e do próprio processo, e ênfase no aspecto monetário, com exclusão das soluções integrativas às questões ${ }^{56}$. A evolução dos institutos está atrelada ao controle difuso e horizontal promovido pelas partes e seus procuradores no seu cotidiano, com enfoque nos aspectos procedimentais do ADR.

Foi observado que em uma década e meia, dentre as 1000 sociedades empresárias estudadas, a regra geral de litigiosidade caiu de 5\% para somente 0,6\% (STIPANOWICH; LAMARE, 2014, p. 32). A diretiva de litigar em juízo e então buscar as ADR (relevante nos fóruns brasileiros) foi reduzida de $24,7 \%$ para $18,8 \%$. Por outro lado, a determinação de buscar a solução alternativa dos conflitos e somente litigar em juízo de maneira subsidiária, aumentou de 25,2\% para 38,2\% do objeto de pesquisa. Já o estabelecimento do uso das ADR como regra plena, não possuiu relevantes variações, de $11,7 \%$ para $11,1 \%$.

É importante ressaltar que 20,8\% das companhias não possuíam qualquer diretiva em relação à litigiosidade, rol ampliado para 25,2\%. Os outros casos reduziram de 12,6\% para $6,1 \%$. Observa-se que a reduzida consultoria jurídica ainda abrange parcela relevante do rol estudado.

Não obstante o custo do serviço de consultoria jurídica, as sociedades empresárias constatam insegurança nas possibilidades de condenações judiciais. A quantidade de normas ${ }^{5758}$, dificuldade no cumprimento das obrigações acessórias ${ }^{59}$ tributárias, trabalhistas e

\footnotetext{
55 "Uma moderna e atualizada compreensão do papel do advogado considera também seu papel pacificador. No contexto de um completo assessoramento de seu cliente, deve o advogado adverti-lo sobre os riscos da demanda e sobre as possibilidades de acordo, orientando-o detalhadamente sobre as implicações decorrentes da adoção de uma ou outra forma de composição de controvérsias" (TARTUCE, 2016, p. 103).

56 "As lawyers firmly embraced mediation, their impact on the process was significant. As portended by responses to the 1994 construction survey, 125 mainstream "legal" mediation typically featured lawyer mediators who at some point in the process employed evaluation techniques - in other words, sharing views on the issues in dispute and their likely disposition in future proceedings. 126 Commentators expressed concern about the pervasiveness of this model to the exclusion of others, as well as other prevalent practices promoted by attorneys, including excessive adversarialism, the manipulation or "spinning" of mediators and of the mediation process, and an overemphasis on monetary settlements to the exclusion of more integrative and "relational" solutions" (STIPANOWICH; LAMARE, 2014, p. 19).

57 "Raríssimas pessoas conhecem o direito fiscal positivo do Brasil, tal a babel de decretos-leis e regulamentos colidentes na sua orientação geral" (BRITO, 1998, p. 82).

58 "A instabilidade, a incompetência, a corrupção e a ditadura da minoria favorecida são frequentes demais. [...] Um comércio prejudicial se desenvolve com a venda, por políticos e por funcionários públicos, de exceções às leis e regulamentações ou de interpretações privilegiadas delas" (GALBRAITH, 1996, p. 152-153).

59 "Cria-se uma "repulsa pela elevada carga tributária, considerada uma das maiores do mundo, e sem uma contraprestação digna que o ser humano merece e garantida pela nossa Constituição" (LOPES, 2006, p. 117).
} 
administrativas, inversão do ônus da prova ope iudicis como técnica de julgamento, e não procedimento (RENHART, 2009), o risco do decisionismo judicial ${ }^{60}$, formalismo ${ }^{61}$, procedimentalismo e custo da jurisdição contribuem para a lógica tentativa de escape da tutela judicial.

Sob o exame do direito estrangeiro, constata-se os fatos acima descritos como algumas razões para a busca das companhias estadunidenses pelas ADR. Evitando-se, assim, quaisquer falsas simetrias entre os sistemas jurídicos.

No caso brasileiro, as ADR também podem servir de mecanismo para o acesso à ordem jurídica justa. Especificamente em relação à mora processual, o Conselho Nacional de Justiça (CNJ) divulga anualmente o relatório Justiça em Números, no qual identifica os principais entraves ao andamento processual (BRASIL, 2019, p. 126). Identificou-se um acervo de 79 milhões de processos em andamento em 2018, com crescente número de ajuizamentos, sendo o próprio Estado o principal litigante ${ }^{62}$. Não obstante a informatização do serviço, coletivização das demandas e ampliação do número de servidores, a heterocomposição é necessariamente dispendiosa e de cognição limitada (em seu sentido material).

Nas ADR, a parte possui a oportunidade de discutir a causa abertamente, inclusive aquilo que não é o seu objeto direto. O contraditório possui relevante relação com a regra da congruência, mas esta é mitigada no âmbito autocompositivo, em especial ${ }^{63}$. Sob outro viés, constata-se ampliação do direito ao contraditório, pois a parte poderá discutir livremente os

\footnotetext{
Busca-se um sistema marcado pela simplicidade e pela certeza: A primeira consiste em uma "legislação de fácil compreensão, acessível aos contribuintes, e de um esquema de arrecadação desburocratizado, célere e de baixo custo" (DAIN, 1995, p. 162).

A última, por sua vez, é marcada pelo "pleno conhecimento da tributação a que estão sujeitos" os contribuintes. (PAULA, 2011, p. 39).

60 "É preciso ir em direção a um constitucionalismo que não faça uso das teses que desembocam, invariavelmente, em discricionariedades. É preciso dar um passo para além do esquema sujeito-objeto. Resgatemos a contribuição básica de Gadamer e Heidegger para fugirmos dessa subjetividade individualista" (SANTOS, 2017, p. 114).

61 "Escrever na forma de leis [...] sua formalidade, muitas vezes, pode servir de justificativa para burocratizar os interesses da maioria e remeter sua consecução para um longo e penoso processo judicial" [...] "existem leis em abundância e pouca efetividade no seu cumprimento" (COUTO, 2010, p. 56).

${ }^{62}$ Não obstante as alegações de indisponibilidade do direito, compreende-se que em grante parte dos casos este argumento não subsiste, em virtude do posicionamento já consolidado dos tribunais superiores sobre disponibilidade do interesse público secundário e ponderação diante da espécie de direito envolvida. Ademais, o judiciário não deve ser o único poder que objetiva o acesso à ordem jurisdicional justa. O Executivo possui o dever constitucional de não sobrepor o interesse público secundário à pretensão de acesso à justiça. Deve promover a pacificação social, ainda que lhe incumba responsabilidade perante outros poderes.

${ }^{63} \mathrm{O}$ exame do contraditório sob o aspecto não procedimental atrai, portanto, uma reflexão sobre o alcance da coisa julgada sobre as prejudiciais de mérito na mediação de conflitos. Frise-se que a coisa julgada foi inicialmente concebida para "encerrar o embate", independentemente da vontade das partes. Logo, a concepção das ADR como negócio jurídico, e menos como quase um "ato-fato", pode mudar a própria forma de se examinar os reflexos da mediação sobre o contraditório e a coisa julgada material.
} 
termos e somente assinará aquilo que acordar (exceto casos de vícios de consentimento, vulnerabilidade ${ }^{64}$ e situações semelhantes).

As diferenças entre as ADR e a clássica concepção monista processual reside na sua própria gênese. Constatando-se as tutelas alternativas como espécies de contrato (e não somente uma decisão processual), torna-se mais simples e aceitável a identificação do respeito ao contraditório na autocomposição.

Observadas semelhanças nas dificuldades enfrentadas pelo processo judicial brasileiro e o estadunidense (não obstante as matrizes distintas no civil e common law), constata-se aspectos positivos no passo a passo estrangeiro de aplicação das ADRs. A mutação na compreensão do processo do seu aspecto monista heteronormativo para o diálogo aberto entre as partes, a sociedade e o próprio judiciário, são lições relevantes para a estruturação da autocomposição como regra no ordenamento jurídico pátrio.

\section{CONSIDERAÇÕES FINAIS}

Compreendidas as dificuldades inerentes à prestação jurisdicional em sua acepção clássica, observa-se a relevância das ADRs, em especial a mediação e a conciliação, ao oportunizarem ao judiciário a atuação em maior número de demandas, sem detrimento da qualidade da prestação do serviço. Frisa-se como benefício a participação popular na construção do próprio direito, permitindo-lhe a emancipação.

Da lição estadunidense é constatada a relevância da superação dos entraves procedimentais na autocomposição dos conflitos, com enfoque no aspecto informal, informatizado e público. A substituição gradativa da noção dos ritos, jargões e enfoque nos fundamentos jurídicos, em prejuízo dos fatos, deve ser aspecto basilar das reformas autocompositivas.

Alterações substanciais no ensino jurídico, por fim, devem compreender as técnicas de negociação como fim, como procedimentos relevantes a superarem o formalismo estrutural.

\footnotetext{
${ }^{64}$ Neste caso, relevante a participação do Ministério Público. Observe-se que, partindo do pressuposto que o MP tem por escopo constitucional a defesa da ordem jurídica, do regime democrático e dos interesses sociais e individuais indisponíveis, e a sua defesa é muito mais ampla que a obrigatoriedade do processo em sua concepção clássica, defende-se juridicamente a atuação do MP como órgão conciliador de fato: promotor da ordem jurídica justa, e não da heterocomposição dos litígios.
} 
A aproximação entre a ciência jurídica e a comunidade permite a promoção do direito na ordem social, assegurando de fato a concretização dos direitos.

\section{REFERÊNCIAS}

BOBBIO, Noberto. A era dos direitos. Rio de Janeiro: Campus, 1992.

BRASIL. Conselho Nacional de Justiça. Justiça em números 2019. Brasília: CNJ, 2019. Disponível em: https://www.cnj.jus.br/pesquisas-judiciarias/justica-em-numeros/. Último acesso em 25 jun. 2020.

BRITO, EDVALDO. A legislação ordinária de cada ente tributante pode estabelecer prazos de decadência (e/ou de prescrição), inclusive das contribuições de seguridade social, diversos dos previstos no Código Tributário Nacional? In: ROCHA, Valdir de Oliveira. Grandes questões atuais do direito tributário. V. 2. São Paulo: Dialética, 1998.

CAPPELLETTI, Mauro; GARTH, Bryant. Acesso à justiça. Trad. NORTHFLEET, Ellen Gracie. Porto Alegre: Sérgio Antônio Fabris Editor. 1988.

CHIOVENDA, Giuseppe. Instituições de direito processual civil. V. 1 Trad. CAPITANIO, Paolo, com anotações de Enrico Tullio Liebman. Campinas: Bookseller, 2000.

COSTA, Eduardo José da Fonseca. Levando a imparcialidade a sério: proposta de um modelo interseccional entre direito processual, economia e psicologia. São Paulo: Pontifícia Universidade Católica de São Paulo. Tese de Doutorado em Direito Processual Civil, 2016.

COUTO, Berenice Rojas. O direito social e a assistência social na sociedade brasileira: uma equação possível? 4. ed.. São Paulo: Cortez, 2010.

DAIN, Sulamis. Experiência internacional e especificidade brasileira. Em: AFFONSO, Rui de Britto Álvares; SILVA, Pedro Luiz Barros (org.). Reforma tributária e federação. São Paulo: FUNDAP: Editora da Universidade Estadual Paulista, 1995.

FISCHER, Roger; Ury, William; PATTON, Bruce. Como chegar ao sim: negociação de acordos sem concessões. Traduzido por Vera Ribeiro e Ana Luiza Borges. 2. Ed. Rio de Janeiro: Imago, 2005. 
GALBRAITH, John Kenneth. A sociedade justa: Uma Perspectiva Humana. Trad. KORYTOWSKI, Ivo. Rio de Janeiro: Campus, 1996.

GARCEZ, José Maria Rossani. Negociação. ADRS. Mediação, conciliação e arbitragem. 2. Ed. Rio de Janeiro: Lumen Juris. 2004.

HABERLE, Peter. Hermenêutica constitucional - A sociedade Aberta dos Intérpretes da Constituição. Gilmar Ferreira Mendes (Tradução). Porto Alegre: Editora Fabris, 1997.

HESSE, Konrad. A força normativa da Constituição. Porto Alegre: Sergio Antonio Fabris Editor, 1991.

IAMAMOTO, M. V. Apresentação. Em: MENEZES, M. T. Em busca da teoria: políticas de assistência pública. São Paulo: Cortez, 1993. P. 11.

LIMA, Rafael Bellem de; VASCONCELOS, Natália Pires de. O sistema de justiça brasileiro: Atores, atuação e consequências do arranjo constitucional. In: FILHO, Naercio Menezes; SOUZA, André Portela (Orgs.). A Carta: para entender a Constituição brasileira. São Paulo: Todavia, 2019. P. 112.

LOPES, Cláudio Célio de Araújo. O modelo IVA de tributação como instrumento para um novo federalismo fiscal brasileiro diante da globalização. Fortaleza: Fundação Edson Queiroz e UNIFOR, 2006.

MILL, John Stuart. Three essays on religion: nature, the utility of religion, theism. Toronto: Toronto University Press. 1969.

NOGUEIRA, Marco Aurélio. A dialética estado/sociedade e a construção da seguridade social pública. São Paulo, ABONG, 2011

PAULA, Felipe Viana de. O impacto do regime de substituição tributária sobre o preço dos produtos derivados do leite no Estado de São Paulo. Piracicaba: Universidade de São Paulo, 2011.

RAICHELIS, R. Esfera pública e conselhos de assistência social: caminhos da construção democrática. São Paulo: Cortez, 1998. 
RAWLS, John. A theory of justice. Trad. PISETTA, Almiro; ESTEVES, Lenita M. R. São Paulo: Martins Fontes, 1997.

RENHART, Sérgio Cruz. Ônus da prova e sua modificação no processo civil brasileiro. In: NEVES, Daniel Amorim Assumpção (Coord.). Aspectos atuais do direito probatório. São Paulo: Método, 2009.

SANTOS, Bruno Aguiar. Neoconstitucionalismo e ativismo: a ideologia fadada ao fracasso do arbítrio. 2017. 127 f. Dissertação (Mestrado em Direito Político e Econômico) Universidade Presbiteriana Mackenzie, São Paulo, 2017.

SARLET, Ingo Wolfgang. A eficácia dos direitos fundamentais. Porto Alegre: Livraria dos Advogados, 2001.

SEN, Amartya. A ideia de Justiça. São Paulo: Companhia das Letras, 2018.

SILVA, Clóvis Veríssimo de Couto e. A teoria das ações em Pontes de Miranda. Em: Revista de informação legislativa, v. 25, n. 100, out./dez. 1988.

SILVA, Clóvis Veríssimo de Couto e. A obrigação como processo. Rio de Janeiro: FGV, 2006.

SMITH, Adam. Teoria dos sentimentos morais. São Paulo: Martins Fontes, 1999.

SPOSATO, Karyna Batista; SILVA, Luciana Aboim Machado da. Justiça juvenil restaurativa e novas formas de solução de conflitos. São Paulo: CLA. 2018.

STIPANOWICH, Thomas J.; LAMARE, Ryan. Living with ADR: Perceptions and use of mediation, arbitration, and conflict management in fortune 1000 corporations. Cambridge: Harvard Negotiation Law Review, v. 19, 2014.

STRECK, Lenio Luiz. Precisamos falar sobre direito e moral: Os problemas da interpretação e da decisão judicial. Florianópolis: Tirant lo Blanch, 2019.

TARTUCE, Fernanda. Mediação nos conflitos civis. 3. ed.. São Paulo: Método. 2016. 